\title{
Passado e presente das forças armadas brasileiras
}

Rodrigo Jurucê Mattos Gonçalves

RESENHA: BARBOSA, Jefferson Rodrigues et al. Militares e política no Brasil. São Paulo: Expressão Popular, 2018.

A editora Expressão Popular recém lançou o livro Militares e política no Brasil, em 2018. A obra é composta por 14 textos, divididos em quatro partes temáticas que tratam das relações dos militares com o Estado, a educação, a imprensa militar, o chauvinismo e o antifascismo. São quinze autores de distintas áreas profissionais e do conhecimento, sendo um filósofo, três cientistas sociais, oito historiadores e três militares de carreira, entre os quais um tem formação em História e Ciências Sociais e o outro em Literatura.

Para aqueles que desejam compreender o passado e o presente das Forças Armadas do Brasil (FAB), sua gênese histórica, suas articulações políticas, sociais e institucionais, bem como a sua problemática ideológica, a obra em questão é fundamental, trazendo pesquisas variadas que abordam a questão militar desde a formação das FAB no século XIX. Levando-se em consideração que, na Nova República, a tutela militar está prevista na Constituição Federal de 1988 e que os militares praticamente formam a espinha dorsal do governo de Bolsonaro, em uma espécie de "junta militar", pode-se dizer que Militares e política no Brasil é uma leitura imprescindível para o momento hodierno. Ela contribui para compreensão de como chegamos à situação descrita pelo prefaciador da obra, Daniel Aarão Reis, segundo o qual durante a elaboração da Constituição de 1988, os militares:

\section{$\overline{\text { Rodrigo Jurucê Mattos GonçAlves }}$}

Doutor em História pelo Programa de Pós-Graduação em História da Universidade Federal de Goiás (PPGH - UFG). Professor do curso de mestrado do Programa de Pós-Graduação em História da Universidade Estadual de Goiás (PPGHIS - UEG), na área de concentração em Cultura e Sociedade. E-mail: rodrigo.goncalves@ueg.br. 
[...] fizeram-se valer, através de lobbies e pressões diversas, garantindo [...] regalias próprias" e "a capacidade de intervir militarmente no jogo político para a 'garantia da lei e da ordem' (GLO). Finalmente, na conjuntura que vivemos nos dias atuais, voltam as Forças Armadas a planar, como sombras, sobre as instituições políticas. (BARBOSA et al., 2018, p. 10 - 11).

Ainda no século XIX, por meio de imprensa própria, os militares criaram em torno de si a imagem de "castidade moral", por um lado, criticando as autoridades civis, políticos e bacharéis (BARBOSA et al. , 2018, p. 253; 282), por outro, ignorando a corrupção que grassava nos quartéis (BARBOSA et al., 2018, p. 270).

Sendo o aparelho repressivo do Estado brasileiro, as FAB não deixariam de herdar muitas das contradições que marcam a ossatura superestrutural do poder burguês. Nesse sentido, disputas marcaram a caserna durante o século XX, com forte polarização ideológica. Com a proclamação da República, emergiu a luta política entre várias facções militares, de modo que a hierarquia e a disciplina chegaram a ser questionadas por jovens praças e oficiais, os quais confrontaram o comando pelo direito de se manifestar politicamente (BARBOSA et al., 2018, p. 23). Além da polarização esquerda/direita, as FAB mostram-se fendidas pela divisão da sociedade de classes.

Nesse sentido, a classe dominante se fez presente ocupando os cargos de alta patente. Sustentava-se no trinômio "hierarquia-disciplina-anticomunismo" (BARBOSA et al., 2018, p. 24), o qual bloqueou a possibilidade de diálogo democrático entre os militares e levou a intervenções diretas na vida política nacional, como os golpes de Estado que marcam a época republicana. O proletariado, representado pelos praças e sargentos, tinham suas demandas ignoradas e podiam ser dispensados sem nenhum direito (BARBOSA et al., 2018, p. 27). Nos anos 1960, reemerge com força o movimento dos sargentos, seguidos dos marinheiros, logo acusados pelos setores conservadores de suposta quebra da hierarquia militar (BARBOSA et al., 2018, p. 39). Com o golpe de 1964, seguiu-se um grande expurgo nas FAB, com um total de 6.591 militares perseguidos (BARBOSA et al., 2018, p. 42). 
O processo tardio de industrialização brasileira demandou forte indução estatal, que veio na forma tanto de apoios institucionais, quanto de uma forte sustentação ideológica, tendo-se feito presentes as FAB em ambos os aspectos (BARBOSA et al., 2018, p. 67). Segundo a "consciência industrialista" (BARBOSA et al. , 2018, p. 68) dos militares, uma nação só poderia ter tropas bem aparelhadas se contasse com uma economia baseada em amplo parque industrial. Essa premissa não deixa de ser verdadeira, mas trouxe em seu interior novas contradições.

Nesse sentido, nos anos 1930, o general Góes Monteiro desenvolvera um conjunto de ideias para o Exército, formando uma doutrina de inspiração autoritária que transbordava para a nação:

O fortalecimento do Estado e da Economia, como forma de garantir a unidade e a independência da nação, e a crítica ao liberalismo e ao comunismo (implícita ou explícita) eram preceitos comuns encontráveis nos pensadores autoritários da época, como Azevedo Amaral, Francisco Campos e Oliveira Vianna (BARBOSA et al., 2018, p. 73).

Nessa época, os militares já tinham uma forte coesão que lhes permitia intervir na sociedade. Isso aliado à vulnerabilidade de Vargas conferiu uma proeminência aos militares, durante o Estado Novo, sendo que foram eles que garantiram o sucesso do golpe e a instauração do regime, em 1937, bem como sua derrubada, em 1945.

Entre 1930 e 1945, foram assistidas diversas revoltas militares, seguidas de expurgos que contribuíram para a coesão pretoriana e conferiram às FAB a estrutura de reserva de poder burguês. Aprofundando essa relação, os militares estabeleceram conexões com o empresariado, sobretudo nos cursos ofertados pela Escola Superior de Guerra (ESG). A participação de empresários como conferencistas era comum, denotando "alto grau de congruência ideológica" com os militares (BARBOSA et al., 2018, p. 93).

A ESG foi criada em 1949, nos moldes do National War College norte-americano, criado pouco antes, em 1946. No entanto, sua relação com as forças armadas dos Estados Unidos ia muito além disso. A ESG adotou a doutrina militar do Pentágono, abrindo mão de estudar por conta própria as grandes questões estratégicas, os 
problemas da guerra e da paz no mundo (BARBOSA et al., 2018, p. 129). Ademais disso, a doutrina da ESG substituiu a "defesa nacional", considerada então "obsoleta", pela "'segurança nacional, isto é, a 'defesa' interna da ordem política e social" (BARBOSA et al., 2018, p. 130). A obsessão pela "defesa interna" e "segurança nacional" já fez o país naufragar na obscuridade, entre 1964 e 1985. Será que poderemos, uma vez mais, assistir a tal decadência da nação?

A seção da obra dedicada à educação militar e à formação dos oficiais tem um caráter não apenas analítico, que é a proposta geral do compêndio, mas traz os relatos de três militares de carreira que foram testemunhas oculares da errática trajetória das FAB no século XX: Bolivar Marinho Soares de Meirelles (general de brigada), Ivan Cavalcanti Proença (coronel de cavalaria) e Sued Castro Lima (coronel aviador).

As informações trazidas a lume por estes três oficiais são provavelmente a parte mais impactante da obra. Neste fragmento, percebe-se certo otimismo com a possibilidade de uma futura renovação da formação nas FAB e a transformação da nação, com o advento de uma democracia popular e de um exército popular (BARBOSA et al., 2018, p. 186). Ao mesmo tempo, revela-se os mais obscuros interstícios da caserna.

A formação e a educação militar tiveram uma época na qual os cursos eram marcados pelo pluralismo, em que os aspirantes e os oficiais tinham contato com diferentes visões de mundo e ideologias. Isso, porém, durou um breve intervalo de tempo, entre os anos 20 e 30 do século passado. A vitória do golpe de 1964 determinou a ascensão do segmento conservador e entreguista, o qual se tornou e se mantém como força hegemônica na caserna, em detrimento das frações nacionalistas (BARBOSA et al., 2018, p. 206). No período pré-golpe de 1964, "O controle dos estabelecimentos [militares] de ensino revelara-se importante instrumento para disseminar o ideário de direita" (BARBOSA et al., 2018, p. 208 - 209). O presidente João Goulart cometera um grave erro ao asilar as escolas oficiais que não tinham sua confiança, presumindo que as academias representassem muito pouco na formação do militar. Após o golpe, a ditadura impôs uma rigorosa fiscalização 
sobre o comportamento dos cadetes, reprimindo qualquer debate sobre questões políticas e sociais (BARBOSA et al., 2018, p. 209). O ensino que passou a ser disseminado a partir de então era altamente ideologizado e os palestrantes da Escola de Comando e Estado-Maior do Exército (ECEME) eram oficiais expoentes da extrema-direita. Somado a isso, é mínima a fração do ensino voltado às Ciências Humanas, as quais poderiam desalienar os alunos (BARBOSA et al., 2018, p. 211).

Após 1985, a democratização não chegou à formação dos militares, fazendo das escolas de formação do oficialato bastiões do autoritarismo e do fascismo. Observa-se nas FAB uma "sólida uniformidade do pensamento político conservador" (BARBOSA et al., 2018, p. 212), evidenciando-se a permanência de cultura antidemocrática nas tropas (BARBOSA et al., 2018, p. 214).

É importante salientar que apesar de os comunistas (civis e militares) historicamente se posicionarem no campo patriótico, defendendo a posse nacional das reservas minerais, essa concepção é em parte compartilhada com a direita militar, a qual insere-se tanto entre as forças nacionalistas, como entre os entreguistas, o seu avesso. Nesse sentido, há uma direita militar entreguista e outra nacionalista (BARBOSA et al., 2018, p. 167), de forma que o campo patriótico tem uma forte divisão interna. A leitura da obra em questão sugere que os militares patrióticos e de esquerda, na sua busca por coerência política, deveriam trilhar o caminho traçado pelo maior quadro intelectual das FAB: Nelson Werneck Sodré (1911 - 1999), o qual reconheceu no povo trabalhador a maior riqueza da nação brasileira. 